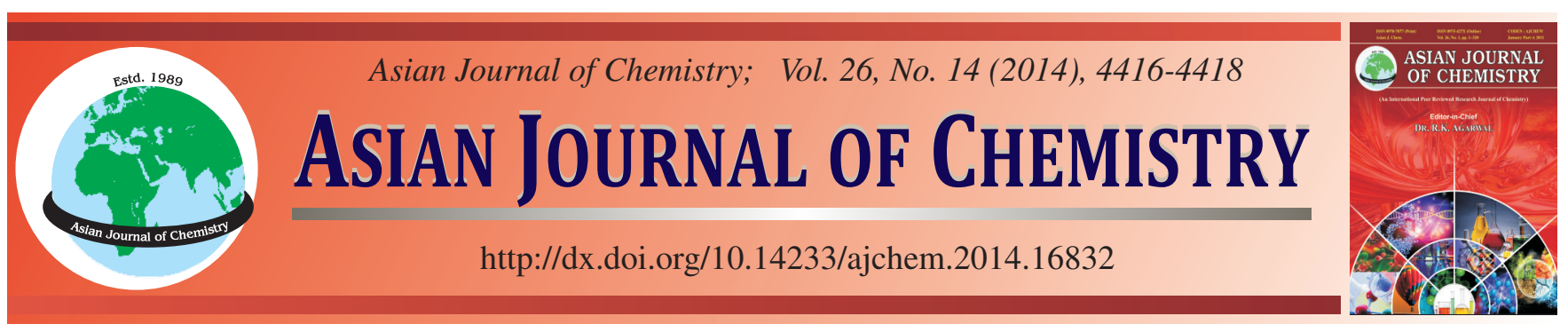

\title{
Determination of Palladium in Surface Water and Gold Ore Samples by Flame Atomic Absorption Spectrophotometry After Pre-concentration with the Porous Nano-calcium Titanate by Sorghum Straw Template Method
}

\author{
YAN Li and DONG ZHANG*
}

School of Environmental and Chemical Engineering, Shenyang Ligong University, Shenyang 110159 P.R. China

*Corresponding author: Tel./Fax: +86 24 24680345; E-mail: sylgdxdong@ sina.com

Received: 6 December 2013;

Accepted: 2 April 2014;

Published online: 5 July 2014;

AJC-15486

A new solid-phase extraction method is described for the determination of traces of palladium in water and geological samples by flame atomic absorption spectrophotometry. The method is based on sorption of Pd ion on the porous nano-calcium titanate by sorghum straw template method (SPCTO). The possible parameters influencing the enrichment were optimized. In the $\mathrm{pH}$ range of 4-7, the Pd ion could be quantitatively retained by the SPCTO. The Pd ion adsorbed on the SPCTO could be completely eluated by using $0.1 \mathrm{~mol} / \mathrm{L} \mathrm{HNO}_{3}$. The enrichment factor was more than 200. Under the optimal solid-phase extraction conditions, the method detection limit was $0.017 \mathrm{ug} / \mathrm{L}$. The established method has been successfully applied to analyze surface water and geological samples. Its accuracy was evaluated by standard addition method and the R.S.D. $(n=6)$ within $4.07 \%$. The recoveries were in the range of 93.8 to $100.9 \%$.

Keywords: Palladium, Porous nano-calcium titanate, Pre-concentration, Surface water, Gold ore.

\section{INTRODUCTION}

It is well known that the palladium is widely applied to the electronics, aerospace industries, chemical, metallurgy, car engines and pharmaceutical industry due to their corrosion resistance, oxidation resistance and excellent catalytic proper$\operatorname{ties}^{1,2}$. In recent years, the development of analytical methods for the determination of trace amounts of precious metals in environmental water ${ }^{3}$, geological ${ }^{4}$, metallurgical and automotive catalyst converter samples ${ }^{5}$ and biological materials ${ }^{6}$ have attracted considerable attention. At present, determining the presence of palladium is typically accomplished by atomic absorption spectrometry (AAS) $)^{1,7}$ and inductively coupled plasma-atomic emission spectroscopy ${ }^{8-10}$. However, the precious metals occur in environmental waters and geological materials at trace and ultratrace levels and their direct determination is beyond the scope of flame atomic absorption spectrometry (AAS). So, a pre-concentration procedure is often required. The widely used techniques for the pre-concentration and separation include solvent extraction ${ }^{11}$, ion-exchange ${ }^{12}$, coprecipitation $^{8}$ and solid phase extraction $(\mathrm{SPE})^{9,13}$, etc. In those techniques, solid phase extraction (SPE) preconcentration and separation has become increasing popular for the determination of trace level of metals. The main solid-phase extraction sorbents are chelating resin ${ }^{14}$, modified barium-strontium titanate powder ${ }^{15}$ and modified silica ${ }^{16}$, etc. With the development of nanomaterial science and technology, nanoparticulate metal oxides, such as $\mathrm{TiO}_{2}, \mathrm{ZnO}$ have been found to have very high adsorption capacity of heavy metal ions from environmental samples ${ }^{17-19}$. Studies have only recently used nano-calcium titanate powders in the adsorption of heavy metals in water for the first time ${ }^{18}$ and the results indicated that nano-calcium titanate powders have higher adsorption capacity than nano-particulate metal oxides. However, the nano-calcium titanate particles are so small that, when used in adsorption of metal ions, it was easy to coacervate and lose activity and are difficult to recover. In order to correct these problems, making the nano-calcium titanate into porous build by sorghum straw template method and used the adsorption of nickel ions in water with satisfactory results ${ }^{20}$. But the porous nano-calcium titanate by sorghum straw template method (SPCTO) use in pre-concentration of palladium has not been studied. In this work, the adsorptive potential of SPCTO for the preconcentration of trace $\mathrm{Pd}(\mathrm{II})$ were assessed using the batch adsorption method. A new method using SPCTO as solid-phase extraction agent has been developed for the preconcentration of trace Pd ion in surface water and gold ore samples analyses by flame atomic absorption spectrophotometry.

\section{EXPERIMENTAL}

A WYX-9003A atomic absorption spectrometer (Shenyang Yi Tong Analytical Instrument Co., Ltd.), equipped with hollow cathode lamp for palladium, was used for palladium determination. The measurements were done in air-acetylene flame and the operation conditions are summarized in Table-1. 


\begin{tabular}{cccccc}
\hline \multicolumn{7}{c}{ TABLE-1 } \\
& FAAS OPERATING CONDITIONS \\
\hline \multirow{2}{*}{ Element } & Wavelength $(\mathrm{nm})$ & $\begin{array}{c}\text { Spectral band width } \\
(\mathrm{nm})\end{array}$ & Lamp current $(\mathrm{mA})$ & Burner height (mm) & $\begin{array}{c}\text { Acetylene gas } \\
\text { consumption (L/min) }\end{array}$ \\
\hline $\mathrm{Pd}$ & 244.8 & 0.2 & 7.5 & 8 & 8 \\
\hline
\end{tabular}

The $\mathrm{pH}$ values were measured with a PHS-3C acidometer (Shanghai REX Instrument Factory, Shanghai, China) supplied with a combined electrode. A bath shaker (Jintan Experiment Instrument Factory, Jiangsu China) was used to shaking for adsorption and desorption experiments.

The porous nano-calcium titanate by sorghum straw template method (SPCTO) was prepared in our laboratory as previously described elsewhere ${ }^{15}$. A stock solution $(1 \mathrm{~g} / \mathrm{L})$ of $\mathrm{Pd}(\mathrm{II})^{21}$ was prepared by dissolving $0.1666 \mathrm{~g}$ of palladium dichloride (Sinopharm Chemical Reagent Co., Ltd, China) in $5 \mathrm{~mL}$ of aqua regia and dilution to $100 \mathrm{~mL}$ with water. Working standards were prepared by appropriate dilution of the stock solution with water daily. All the chemicals were guaranteed reagents grade. The water in this study was double-quartz sub-boiling distilled water.

General procedure: A quantity of $\mathrm{Pd}(\mathrm{II})$ solution was placed into a $150 \mathrm{~mL}$ (or $1000 \mathrm{~mL}$ ) calibrated Erlenmeyer flask with plug. The $\mathrm{pH}$ was adjusted to $4-10$ with hydrochloric acid or sodium hydroxide solution. After diluting to the mark of $50 \mathrm{~mL}$ (or other volume) with water, $0.1 \mathrm{~g}$ of SPCTO was added. Covered with a plug, the Erlenmeyer flask was shaken for $5 \mathrm{~min}$ in the bath shaker. Filtrated using filter, then the concentration of $\operatorname{Pd}(\mathrm{II})$ in filtrate was determined by flame atomic absorption spectrophotometry and absorption capacity was calculated. Then the adsorbent was washed with water to remove any unadsorbed $\mathrm{Pd}(\mathrm{II})$, the adsorbed $\mathrm{Pd}(\mathrm{II})$ was eluted with $5 \mathrm{~mL}$ of $0.1 \mathrm{~mol} / \mathrm{L} \mathrm{HNO}_{3}$ solution by shaking for $5 \mathrm{~min}$. The concentrations of the $\mathrm{Pd}(\mathrm{II})$ in the eluents was determined by flame atomic absorption spectrophotometry and the recovery was calculated.

\section{RESULTS AND DISCUSSION}

Effect of pH on the adsorption: In order to study the effect of $\mathrm{pH}$ on the adsorption, the $\mathrm{pH}$ was adjusted in the ranges of 1-12 using hydrochloric acid or sodium hydroxide solution and then the adsorption procedure described was applied. The results are shown in the Fig. 1. The adsorption percentage of SPCTO to Pd(II) was high and pH dependent. Increasing $\mathrm{pH}$ resulted in an increase of adsorption capacity. The adsorption percentage of $\mathrm{Pd}(\mathrm{II})$ at the $\mathrm{pH}$ range of 4 to 12 was $100 \%$. In order to avoid the precipitation of metal ions at high concentration, $\mathrm{pH}$ 4-7 was selected as the optimal condition.

Effect of shaking time on the adsorption: In order to study the influence of contact time on the adsorption of $\mathrm{Pd}(\mathrm{II})$ onto SPCTO, the adsorption capacity was determined at different shaking time. The results are showed in Fig. 2. It is seen that the reaction of adsorption was very quickly and reached equilibrium at $3 \mathrm{~min}$. In order to complete the reaction, the shaking time was $5 \mathrm{~min}$ in this study. The capability of adsorption was $50 \mathrm{mg} / \mathrm{g}$.

Elution: Base on Fig. 1, the adsorption percentages of $\mathrm{Pd}(\mathrm{II})$ on the SPCTO was zero when $\mathrm{pH}$ value no more than 2. Therefore, after adsorption under the optimized adsorption

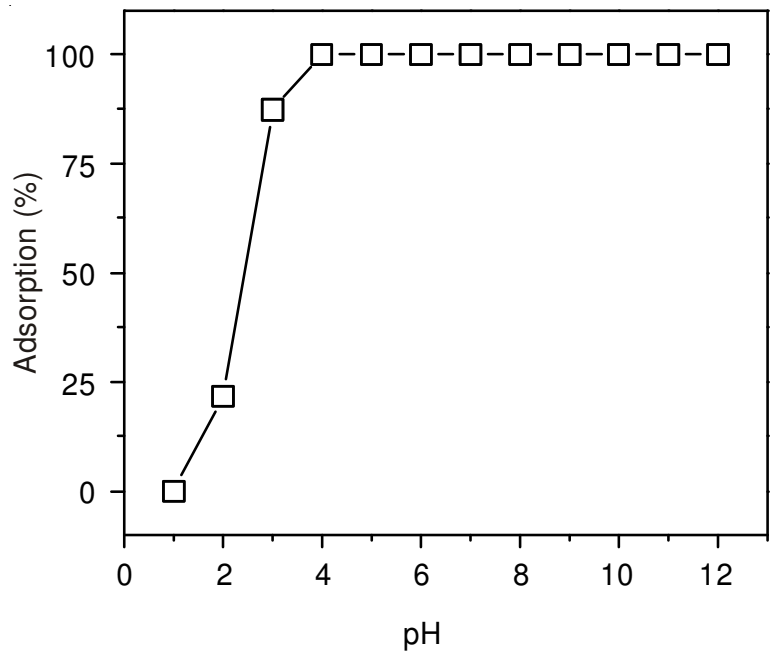

Fig. 1. Effect of $\mathrm{pH}$ on the adsorption

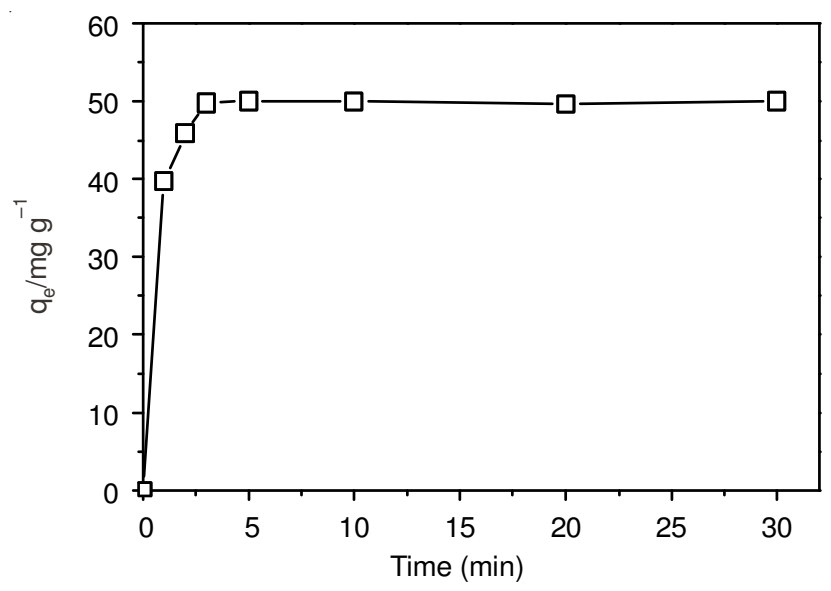

Fig. 2. Effect of contact time on Pd(II) adsorption

conditions, $5 \mathrm{~mL}$ of $\mathrm{HNO}_{3}$ at different concentration $(0.001$ $\mathrm{mol} / \mathrm{L}^{-1} 1 \mathrm{~mol} / \mathrm{L}$ ) were chosen to be eluents in desorption of $\mathrm{Pd}(\mathrm{II})$ adsorbed on SPCTO by shaking $5 \mathrm{~min}$.

The results showed that desorption recovery increased with an increase of $\mathrm{HNO}_{3}$ concentration. When the concentration of $\mathrm{HNO}_{3}$ was higher than $0.01 \mathrm{~mol} / \mathrm{L}$, the recoveries were up to $98 \%$. So, for sufficient elution, in this paper, $5 \mathrm{~mL}$ of $0.1 \mathrm{~mol} / \mathrm{L} \mathrm{HNO}_{3}$ was chosen.

After elution, the SPCTO was dried under $105{ }^{\circ} \mathrm{C}$ and reused 10 times. Its adsorption performance did not decrease, indicating that this adsorption agent was very stable.

Enrichment factor and detection limit: For studied the possibility of pre-concentration low concentrations of Pd(II) from large volumes, $25 \mu \mathrm{g}$ of $\mathrm{Pd}(\mathrm{II})$ was dissolved in various volume (including 20, 50, 100, 250, 500, 750, and $1000 \mathrm{~mL}$ ) of water together. After adsorption, the SPCTO were eluted with $5 \mathrm{~mL}$ of elution liquid. The amounts recovered are listed in Table-2. It could be seen that when the solution volume was $1000 \mathrm{~mL}$, the recovery was above $92 \%$. The enrichment factor was 200 . 


\begin{tabular}{|c|c|c|c|}
\hline \multicolumn{4}{|c|}{ DETERMINATION OF PALLADIUN } \\
\hline Samples & \multicolumn{2}{|c|}{ Found $(\mu \mathrm{g} / \mathrm{L})$} & RSD $(\%)$ \\
\hline Hun-he river & \multicolumn{2}{|c|}{8.64} & 2.74 \\
\hline Nan-hu lake & \multicolumn{2}{|c|}{12.82} & 1.96 \\
\hline \multicolumn{4}{|c|}{ DETERMINATION OF PALLAI } \\
\hline Samples & \multicolumn{2}{|c|}{ Found (g/ton) } & $\operatorname{RSD}(\%)$ \\
\hline Sample 1 & \multicolumn{2}{|c|}{1.538} & 4.07 \\
\hline Sample 2 & \multicolumn{2}{|c|}{1.141} & 2.68 \\
\hline Sample 3 & \multicolumn{2}{|c|}{0.879} & 3.94 \\
\hline \multicolumn{4}{|c|}{$\begin{array}{c}\text { TABLE-2 } \\
\text { PRECONCENTRATION AND RECOVERY OF PALLADIUM }\end{array}$} \\
\hline $\begin{array}{l}\text { Volume of the } \\
\text { solution (mL) }\end{array}$ & $\begin{array}{l}\text { Quantity in } \\
\text { eluent }(\mu \mathrm{g})\end{array}$ & $\begin{array}{l}\text { Recovery } \\
(\%)\end{array}$ & $\begin{array}{l}\text { Enrichment } \\
\text { factor }\end{array}$ \\
\hline 20 & 25.35 & 101.4 & 4 \\
\hline 50 & 24.94 & 99.76 & 10 \\
\hline 100 & 24.65 & 98.6 & 20 \\
\hline 250 & 23.88 & 95.52 & 50 \\
\hline 500 & 23.76 & 95.04 & 100 \\
\hline 750 & 23.22 & 92.88 & 150 \\
\hline 1000 & 23.46 & 93.84 & 200 \\
\hline
\end{tabular}

The detection limits $(3 \times$ S.D. $)$ were calculated using procedural blank consisting of $200 \mathrm{~mL}$ water, $0.5 \mathrm{~g}$ SPCTO taken through entire procedure and calculated from 11 runs of the blank solution with concentrations of $\mathrm{Pd}(\mathrm{II})$ at $0.017 \mu \mathrm{g} / \mathrm{L}$. The relative standard deviations (RSD) for $\mathrm{Pd}(\mathrm{II})$ was $2.3 \%$ $\left(\mathrm{n}=11, \mathrm{C}_{\mathrm{Pd}}=10 \mu \mathrm{g} / \mathrm{L}\right)$.

Effect of the interfering ions: The effects of common coexisting ions on the adsorption of $\mathrm{Pd}(\mathrm{II})$ was studied. Various interference ions were added into a $100 \mathrm{~mL}$ volumetric flask containing $10 \mu \mathrm{g}$ of $\mathrm{Pd}(\mathrm{II})$. The results showed that recoveries of the $\mathrm{Pd}(\mathrm{II})$ remained in $95-105 \%$ even in the presence of ions in the following concentrations: $1000 \mathrm{mg} / \mathrm{L}$ for $\mathrm{Na}^{+}, \mathrm{K}^{+}$, $\mathrm{NH}_{4}^{+}$and $\mathrm{NO}_{3}{ }_{3}^{-} ; 500 \mathrm{mg} / \mathrm{L}$ for $\mathrm{Ca}^{2+}, \mathrm{Mg}^{2+}, \mathrm{Al}^{3+}$ and $\mathrm{PO}_{4}{ }_{4}^{3-} ; 200$ $\mathrm{mg} / \mathrm{L}$ for $\mathrm{Cr}(\mathrm{III}), \mathrm{Co}^{2+}, \mathrm{Cr}(\mathrm{VI})$ and $\mathrm{Cu}^{2+} ; 100 \mathrm{mg} / \mathrm{L}$ for $\mathrm{Zn}^{2+}$, $\mathrm{Ni}^{2+}, \mathrm{Fe}^{3+}, \mathrm{Au}(\mathrm{III}), \mathrm{Pt}(\mathrm{IV}) ; 10 \mathrm{mg} / \mathrm{L}$ for $\mathrm{Pb}^{2+}$ and $\mathrm{Cd}^{2+}$.

Application of the method: The present procedure was applied to various waters, such as river water and lake water. The surface waters were collected from the Hun-he river and Nan-hu lake (Shenyang, China). $100 \mathrm{~mL}$ of water sample was pre-concentrated using optimized solid-phase extraction technique after digestion process with concentrated nitric acid. The obtained results and the associated recovery are shown in Table-3.

The proposed method was also applied to gold ore (obtained from a mining company of Liaoning) at optimum conditions. Each mine stone was grinded and proper amount of it was weighted in the range of 4-6 $\mathrm{g}$ and digested in aqua regia by refluxing the mixture for $12 \mathrm{~h}$. The solution of each sample was filtered. The filtered solution was diluted with concentrated nitric acid up to $25 \mathrm{~mL}$. Finally, $5 \mathrm{~mL}$ of this solution was poured into volumetric flask and after adjustment of $\mathrm{pH}$, the volume of solution was adjusted to $50 \mathrm{~mL}$. The solution was then adsorbed and eluted using the proposed method at the optimal conditions. The blanks were prepared in the same way as the sample, but omitting the sample. The analytical results and the associated recovery are given in Table- 4 .

The recovery was 93.8-100.9\%, which were excellent for trace analysis. So, the proposed method was demonstrated the suitability of this sorbent for the pre-concentration and determination of trace palladium.

\section{Conclusion}

According to the present results, it could be concluded that $\mathrm{Pd}(\mathrm{II})$ could be quantitatively retained by the SPCTO in the $\mathrm{pH}$ of 4-7, the adsorption time was 5 min and capability of adsorption was $50 \mathrm{mg} / \mathrm{g}$. The Pd(II) adsorbed on the SPCTO could be completely eluated by using $5 \mathrm{~mL} 0.1 \mathrm{~mol} / \mathrm{L} \mathrm{HNO}_{3}$. The enrichment factor was more than 200 . The detection limit of this method for Pd(II) was $0.017 \mu \mathrm{g} / \mathrm{L}$. The proposed method has been applied to the determination of trace amounts of palladium in water and gold ore with satisfactory results.

\section{REFERENCES}

1. S. Tokalioglu, T. Oymak and S. Kartal, Anal. Chim. Acta, 511, 255 (2004).

2. F. Zereini and F. Alt, Palladium Emission in the Environment, SpringerVerlag, Berlin Heidelberg (2006).

3. S. Saçmaci and S. Kartal, Talanta, 109, 26 (2013).

4. G. Chakrapani, P.L. Mahanta, D.S.R. Murty and B. Gomathy, Talanta, 53, 1139 (2001).

5. A.N. Anthemidis, D.G. Themelis and J.A. Stratis, Talanta, 54, 37 (2001).

6. Z. Fan, Z. Jiang, F. Yang and B. Hu, Anal. Chim. Acta, 510, 45 (2004).

7. P. Liang, E. Zhao and F. Li, Talanta, 77, 1854 (2009).

8. P. Petrova, S. Velichkov, N. Velitchkova, I. Havezov and N. Daskalova, Spectrochim. Acta B, 65, 130 (2010).

9. M. Moldovan, M.M. Gómez and M.A. Palacios, Anal. Chim. Acta, 478, 209 (2003).

10. J. Nakajima, M. Ohno, K. Chikama, T. Seki and K. Oguma, Talanta, 79, 1050 (2009).

11. S. Igarashi, N. Ide and Y. Takagai, Anal. Chim. Acta, 424, 263 (2000).

12. P. Kovacheva and R. Djingova, Anal. Chim. Acta, 464, 7 (2002).

13. M.D. Farahani, F. Shemirani and M. Gharehbaghi, Talanta, 109, 121 (2013).

14. T. Çetin, S. Tokalioglu, A. Ülgen, S. Sahan, I. Özentürk and C. Soykan, Talanta, 105, 340 (2013).

15. D. Zhang and P. Yu, Asian J. Chem., 24, 1715 (2012).

16. R.K. Sharma, A. Pandey, S. Gulati and A. Adholeya, J. Hazard. Mater., 209-210, 285 (2012).

17. D. Zhang, H.D. Su and H. Gao, Spectrosc. Spect. Anal., 28, 218 (2008).

18. D. Zhang and P. Hou, Acta Chim. Sin., 67, 1336 (2009).

19. D. Zhang, C.L. Zhang and P. Zhou, J. Hazard. Mater., 186, 971 (2011).

20. D. Zhang, M. Wang, G.J. Ren and E.J. Song, Mater. Sci. Eng. C, 33, 4677 (2013). 